\title{
On Fuzzy Supra Baire Spaces
}

\section{E. Poongothai'., A. Celine ${ }^{2}$}

PG \& Research Department of Mathematics, Shanmuga Industries Arts \& Science College, Tiruvannamalai - 606603, Tamil Nadu, India

ABSTRACT: The idea of this paper is to introduce the concepts of fuzzy supra Baire spaces by means of fuzzy supra nowhere dense set in fuzzy supra topological spaces with suitable examples to illustrate the concepts. Several characterizations of fuzzy supra Baire spaces are also studied.

KEYWORDS: Fuzzy supra dense, Fuzzy supra $F_{\sigma}$ - set, Fuzzy supra-G $\delta$ set, Fuzzy supra first category, Fuzzy supra second category, Fuzzy Supra residual set.

https://doi.org/10.29294/IJASE.8.3.2022.2310-2313

C2022 Mahendrapublications.com, All rights reserved

\section{INTRODUCTION}

Zadeh [10] was first introduced in 1965 the concept of fuzzy sets and fuzzy set operations in his classical paper. In 1968, the theory of fuzzy topological spaces was introduced and developed by Chang [3]. In 1977, Haworth and McCoy [4], introduced and studied the concept of Baire spaces in topological spaces. In 1987, AbdElmonsef et at [1] introduced and defined the basic notions of fuzzy supra topological spaces. The idea of this paper is to introduce the concepts of fuzzy supra Baire space in fuzzy supra topological spaces with examples by using fuzzy supra nowhere dense set. The several characterizations of fuzzy supra Baire spaces are obtained.

\section{Preliminaries}

\section{Definition 2.1[2]}

A collection $\delta^{*}$ of fuzzy sets in a set $\mathrm{X}$ is called fuzzy supra topology on $\mathrm{X}$ if the following conditions are satisfied:

1) $\mathbf{0}$ and $\mathbf{1}$ belongs to $\delta^{*}$.

2) $g_{\chi} \in \delta^{*}$ for each $\chi \in \Lambda$ implies $\left(v_{\chi} \in \Lambda g_{\chi}\right) \in \delta^{*}$.

The pair $\left(\mathrm{X}, \delta^{*}\right)$ is called a fuzzy supra topological space. The elements of $\delta^{*}$ are called fuzzy supra open sets and the complement of a fuzzy supra open set is called fuzzy supra closed set.

\section{Definition 2.2 [5 ].}

The closure and interior of a fuzzy set $f \in \mathrm{I}^{\mathrm{X}}$ are defined respectively as

$\mathrm{cl}^{*}(\mathrm{~g})=\Lambda\{\mathrm{h} / \mathrm{h}$ is a fuzzy closed set in $\mathrm{X}$ and $\mathrm{g} \leq \mathrm{h}\}$

$\operatorname{int}^{*}(\mathrm{~g})=\mathrm{v}\{\mathrm{h} / \mathrm{h}$ is a fuzzy open set in $\mathrm{X}$ and $\mathrm{h} \leq \mathrm{g}\}$

Clearly $\mathrm{cl}^{*}(\mathrm{~g})$ is the smallest fuzzy closed set containing $g$ and $\operatorname{int}^{*}(\mathrm{~g})$ is the largest fuzzy open set contained in $\mathrm{g}$.

\section{Lemma 2.3 [5 ]}

For a fuzzy set $\lambda$ in a fuzzy supra topological space $X$,

(i) $1-\operatorname{int}^{*}(\chi)=\operatorname{cl}^{*}(1-\chi)$,

(ii) $1-\mathrm{cl}^{*}(\chi)=\operatorname{int}^{*}(1-\chi)$.

\section{Definition 2.4 [6]}

A fuzzy supra open set $\chi$ in $\operatorname{FSTS}\left(X, T^{*}\right)$ is called fuzzy supra $F_{\sigma}$ set in $\left(\mathrm{X}, \mathrm{T}^{*}\right)$ if $\quad \chi=\mathrm{v}_{\mathrm{i}=1^{\infty}}\left(\chi_{\mathrm{i}}\right)$, where $1-\chi_{\mathrm{i}} \in \mathrm{T}^{*}$ for $\mathrm{i} \in \mathrm{I}$,

\section{Definition 2.5 [ 6]}

A fuzzy supra open set $\chi$ in FSTS $\left(X, T^{*}\right)$ is called fuzzy supra $G_{\sigma}$ set in $\left(X, T^{*}\right)$ if $\chi=\wedge_{i=1}^{\infty}\left(\chi_{i}\right)$, where $\chi$ $i \in T^{*}$ for $\mathrm{i} \in \mathrm{I}$.

\section{Definition 2.6 [6]}

A fuzzy set $\chi$ in a FSTS $\left(X, T^{*}\right)$ is called a FS dense if there exists no FS closed set $\beta$ in $\left(\mathrm{X}, \mathrm{T}^{*}\right)$ such that $\chi<\beta<1$. That is, $\operatorname{cl}^{*}(\chi)=1$, in $\left(X, T^{*}\right)$.

\section{3 . FUZZY SUPRA NOWHEREDENSE SET}

\section{Definition 3.1 [6]}

A fuzzy set $\chi$ in FSTS $\left(X, T^{*}\right)$ is called a fuzzy supra nowhere dense set if there exists no nonzero fuzzy supra open set $\mu$ in $\left(\mathrm{X}, \mathrm{T}^{*}\right)$ such that $\mu<$ $\mathrm{cl}^{*}(\chi)$. That is, int* $\mathrm{cl}^{*}(\chi)=0$, in $\left(\mathrm{X}, \mathrm{T}^{*}\right)$.

\section{Proposition 3.1}

If $\chi$ is a fuzzy supra closed set in (X,T*),with $\operatorname{int}^{*}(\chi)=0$ then $\chi$ is a fuzzy supra nowhere dense set in $\left(X, T^{*}\right)$ 


\section{Proof}

Let $\chi$ is a fuzzy supra closed set in $\left(X, T^{*}\right)$ then $\operatorname{cl}^{*}(\chi)=\chi$, Now $\operatorname{int}^{*} \mathrm{cl}^{*}(\chi)=\operatorname{int}^{*}(\chi)=0$ and hence $\chi$ is a fuzzy supra nowhere dense set in $\left(X, T^{*}\right)$.

\section{Proposition 3.2}

If the fuzzy sets $\chi$ and $\mu$ are fuzzy supra nowhere dense sets in a fuzzy supra topological space $\left(\mathrm{X}, \mathrm{T}^{*}\right)$. Then $\chi \wedge \mu$ is a fuzzy supra nowhere dense set in $\left(\mathrm{X}, \mathrm{T}^{*}\right)$.

\section{Proof}

Let the fuzzy sets $\chi$ and $\mu$ are fuzzy supra nowhere dense sets in $\left(X, T^{*}\right)$. Now $\operatorname{int}^{*} \mathrm{cl}^{*}(\chi \wedge$ $\mu) \leq \operatorname{int}^{*} \mathrm{cl}^{*}(\chi) \wedge \operatorname{int}^{*} \mathrm{Cl}^{*}(\mu) \leq 0 \wedge 0\left(\right.$ since int ${ }^{*} \mathrm{cl}^{*}(\chi)=0$ and int $\left.^{*} \mathrm{cl}^{*}(\mu)=0\right)$. That is, int ${ }^{*} \mathrm{ll}^{*}(\chi \wedge \mu)=0$. Hence $(\chi$ $\wedge \mu)$ is a fuzzy supra nowhere dense set in $\left(X, T^{*}\right)$.

\section{Proposition 3.3}

If $\chi$ is a fuzzy supra nowhere dense set is a fuzzy supra topological space $\left(X, T^{*}\right)$. Then $\operatorname{int}^{*} \mathrm{cl}^{*}(\chi)=0$.

\section{Proof}

Let $\chi$ be a fuzzy supra nowhere dense set in $\left(\mathrm{X}, \mathrm{T}^{*}\right)$.Then we have $\operatorname{int}^{*} \mathrm{cl}^{*}(\chi)=0 \operatorname{Nowcl}^{*}(\chi)=\chi$, since $\chi$ is fuzzy supra closed set in $\left(X, T^{*}\right)$ this implies that $\operatorname{int}^{*} \operatorname{cl}^{*}(\chi)=\operatorname{int}^{*}(\chi)=0$. Hence $\operatorname{int}^{*} \mathrm{cl}^{*}(\chi)$ $=0$.

\section{Proposition 3.4}

If $\chi$ is a fuzzy supra nowhere dense set and $\mu$ is any fuzzy supra set is a fuzzy supra topological space $\left(X, T^{*}\right)$ then $(\chi \wedge \mu)$ is a fuzzy supra nowhere dense set in $\left(X, T^{*}\right)$.

\section{Proof}

Let $\chi$ be a fuzzy supra nowhere dense set in $\left(\mathrm{X}, \mathrm{T}^{*}\right)$.Then, int $^{*} \mathrm{cl}^{*}(\chi)=0$.Now int ${ }^{*} \mathrm{cl}^{*}(\chi \wedge \mu) \leq$ int $^{*} \mathrm{cl}^{*}$ $(\chi) \wedge$ int $^{*} \mathrm{cl}^{*}(\mu) \leq 0 \wedge$ int $^{*} \mathrm{cl}^{*}(\mu)=0$ that is, int ${ }^{*} \mathrm{cl}^{*}(\chi$ $\wedge \mu)=0$. Hence $(\chi \wedge \mu)$ is a fuzzy supra nowhere dense set in $\left(X, T^{*}\right)$.

\section{Proposition 3.5}

If $\chi$ is a fuzzy supra dense and fuzzy supra open set in a fuzzy supra topological space $\left(\mathrm{X}, \mathrm{T}^{*}\right)$ and if $\chi \leq 1-\mu$, then $\mu$ is a fuzzy supra nowhere dense set in $\left(X, T^{*}\right)$.

\section{Proof}

Let $\chi$ be a fuzzy supra dense set in $\left(\mathrm{X}, \mathrm{T}^{*}\right)$ then we have $\operatorname{cl}^{*}(\chi)=1$ and $\operatorname{int}^{*}(\chi)=\chi$.Now $\mu \leq 1-\chi$, this implies that $\operatorname{cl}^{*}(\mu) \leq \operatorname{cl}^{*}(1-\chi)$.Thencl$l^{*}(\mu) \leq$ $1-\operatorname{int}^{*}(\chi)=1-\quad \chi w h i c h$ implies that $\operatorname{int}^{*} \mathrm{cl}^{*}(\mu)$ $\operatorname{sint}^{*}(1-\chi)=1-\operatorname{cl}^{*}(\chi)=1-1=0$.That is $\operatorname{int}^{*} \operatorname{cl}^{*}(\mu)$ $=0$. Hence $\mu$ is a fuzzy supra nowhere dense set in $\left(\mathrm{X}, \mathrm{T}^{*}\right)$.

\section{Proposition 3.6}

If $\chi$ is a fuzzy supra nowhere dense set in a fuzzy supra topological space $\left(\mathrm{X}, \mathrm{T}^{*}\right)$, then $1-\chi$ is a fuzzy supra dense set in $\left(\mathrm{X}, \mathrm{T}^{*}\right)$.

\section{Proof}

Let $\chi$ be a fuzzy supra nowhere dense set in $\left(\mathrm{X}, \mathrm{T}^{*}\right)$.Then,int ${ }^{*} \mathrm{cl}^{*}(\chi)=0$.Now $\chi \leq \mathrm{cl}^{*}(\chi)$ implies that int $^{*}(\chi) \leq \operatorname{int}^{*} \mathrm{cl}^{*}(\chi)=0$. Then int $(\chi)=0$. Nowcl ${ }^{*}(1-$ $\chi)=1-\operatorname{int}^{*}(\chi)=1-0=1$, then $\mathrm{cl}^{*}(1-\chi)=1$. Hence $1-$ $\chi$ is a fuzzy supra dense set in $\left(X, T^{*}\right)$.

\section{Proposition3.7}

If $\chi$ is a fuzzy supra nowhere dense set in a fuzzy supra topological space $\left(\mathrm{X}, \mathrm{T}^{*}\right)$,then $\mathrm{cl}^{*}(\chi)$ is also a fuzzy supra nowhere dense set in $\left(X, T^{*}\right)$.

\section{Proof}

Let $\chi$ be a fuzzy supra nowhere dense set in $\left(X, T^{*}\right)$.Then, int ${ }^{*} \mathrm{cl}^{*}(\chi)=0$. Now $\operatorname{cl}^{*} \mathrm{cl}^{*}(\chi)=\mathrm{cl}^{*}(\chi)$. Now int* $\operatorname{cl}^{*}\left(\mathrm{cl}^{*}(\chi)\right)=$ int $^{*} \mathrm{cl}^{*}(\chi)=0$. Implies that $\operatorname{int}^{*} \operatorname{cl}^{*}\left(\mathrm{cl}^{*}(\chi)\right)=0$. Therefore $\operatorname{cl}^{*}(\chi)$ is also a fuzzy supra nowhere dense set in $\left(\mathrm{X}, \mathrm{T}^{*}\right)$.

\section{Proposition 3.8}

If $\chi$ be a fuzzy supra closed set in a fuzzy supra topological space $\left(X, T^{*}\right)$ and $\operatorname{if}^{*}(\chi)=0$, then $\chi$ is a fuzzy supra nowhere dense set in $\left(X, T^{*}\right)$.

\section{Proof}

Let $\chi$ be a fuzzy supra closed set in $\left(\mathrm{X}, \mathrm{T}^{*}\right)$. Then we have $\mathrm{cl}^{*}(\chi)=\chi$. Now int ${ }^{*} \mathrm{cl}^{*}(\chi)=\operatorname{int}^{*}(\chi)$ and int $(\chi)=0$ implies that int ${ }^{*} \mathrm{cl}^{*}(\chi)=0$. Hence $\chi$ is a fuzzy supra nowhere dense set in $\left(\mathrm{X}, \mathrm{T}^{*}\right)$.

\section{Definition 3.2}

A fuzzy set $\chi$ in a FSTS $\left(X, T^{*}\right)$ is called a FS first category set if $\chi=v_{i=1}^{\infty}\left(\chi_{i}\right)$, where $\left(\chi_{i}\right)^{\prime}$ s are FS nowhere dense set in $\left(X, T^{*}\right)$. Any other fuzzy set in $\left(\mathrm{X}, \mathrm{T}^{*}\right)$ is said to be FS second category.

\section{Definition 3.3}

A Fuzzy supra topological space $\left(X, T^{*}\right)$ is called a Fuzzy supra first category if $\mathrm{v}_{\mathrm{i}=1^{\infty}}\left(\chi_{\mathrm{i}}\right)=1$, where $\left(\chi_{i}\right)^{\prime} s$ are Fuzzy supra nowhere dense set in $\left(X, T^{*}\right)$. A topological space which is not of Fuzzy supra first category, is said to be Fuzzy supra second category.

\section{Definition 3.4}

Let $\chi$ a fuzzy supra first category set in $\left(\mathrm{X}, \mathrm{T}^{*}\right)$, Then $1-\chi$ is called a fuzzy supra residual set in $(X$, $\left.\mathrm{T}^{*}\right)$.

\section{Proposition 3.9}

If $\chi$ is a fuzzy supra first category set in a fuzzy supra topological space $\left(\mathrm{X}, \mathrm{T}^{*}\right)$, then $1-\chi$ $=\Lambda_{i=1}^{\infty}\left(\chi_{i}\right)$, where $\operatorname{cl}^{*}\left(\mu_{i}\right)=1$.

\section{Proof}


Let $\chi$ be a fuzzy supra first category set in $\left(\mathrm{X}, \mathrm{T}^{*}\right)$. Then we have $\chi=V_{i=1}^{\infty}\left(\chi_{i}\right)$, where $\chi_{i}^{\prime}$ s are fuzzy supra nowhere dense sets in $\left(\mathrm{X}, \mathrm{T}^{*}\right)$.Now $1-\chi=1-$ $\bigvee_{i=1}^{\infty}\left(\chi_{i}\right)=\Lambda_{i=1}^{\infty}\left(\chi_{i}\right)$. Let $\mu_{i}=1-\chi_{i}$. Then $1-\chi=\Lambda_{i=1}^{\infty}\left(\chi_{i}\right)$. Since $\chi_{i}^{\prime}$ sare fuzzy supra nowhere dense sets in $\left(\mathrm{X}, \mathrm{T}^{*}\right)$,by proposition 3.6 , we have $1-\chi_{\mathrm{i}}$ 's are fuzzy supra dense sets in $\left(X, T^{*}\right)$. Hence $\operatorname{cl}^{*}\left(\mu_{\mathrm{i}}\right)=\mathrm{cl}^{*}(1-$ $\left.\chi_{i}\right)=1$, therefore we have $1-\chi=\Lambda_{i=1}^{\infty}\left(\chi_{i}\right)$ where $\operatorname{cl}^{*}\left(\mu_{\mathrm{i}}\right)=1$.

\section{FUZZY SUPRA BAIRE SPACE}

\section{Definition 4.1}

Let $\left(X, T^{*}\right)$ be a Fuzzy supra topological Spaces. Then $\left(X, T^{*}\right)$ is called a Fuzzy supra Baire Spaces if $\operatorname{int}^{*}\left(\mathrm{~V}_{\mathrm{i}=1^{\infty}}\left(\chi_{\mathrm{i}}\right)\right)=0$, where $\left(\chi_{\mathrm{i}}\right)^{\prime} \mathrm{s}$ are Fuzzy supra nowhere dense set in $\left(X, T^{*}\right)$.

EXAMPLE 4.1: Let $X=\{a, b, c\}$. The fuzzy sets $\lambda, \mu$ and $\gamma$ are defined on $X$ as follows:

$\lambda: X \rightarrow[0,1]$ is defined as $\lambda(a)=1 ; \lambda(b)=0.2$; $\lambda(\mathrm{c})=0.7$

$\mu: X \rightarrow[0,1]$ is defined as $\mu(\mathrm{a})=0.3 ; \mu(\mathrm{b})=1$; $\mu(\mathrm{c})=0.2$

$\gamma: X \rightarrow[0,1]$ is defined as $\gamma(a)=0.7 ; \gamma(b)=0.4$;

$\gamma(\mathrm{c})=1$

Then, $T^{*}=\{0, \lambda, \gamma, \gamma \vee \lambda, \gamma \wedge \lambda, 1\}$ and $S^{*}=\{0, \mu, \gamma$, $\gamma \vee \mu, \gamma \wedge \mu, 1\}$ are fuzzy supra topologies on $X$ and the fuzzy supra nowhere dense sets are $1-\lambda, 1-\gamma$, $1-(\gamma \vee \lambda), 1-(\gamma \wedge \lambda))$ in $\left(\mathrm{X}, \mathrm{T}^{*}\right)$. Now $[(1-\lambda) \vee(1-\gamma)$ $\vee(1-(\gamma \vee \lambda)) \vee(1-(\gamma \wedge \lambda))]=1-(\gamma \wedge \lambda)$ and $\operatorname{int}^{*}[1-(\gamma \wedge \lambda$ )$]=0$. Hence $\left(X, T^{*}\right)$ is a fuzzy supra Baire space.

On the other hand the fuzzy supra nowhere dense sets are 1- $\mu, 1-\gamma, 1-(\gamma \vee \mu)$ in $\left(X, S^{*}\right)$. Now [(1$\mu) \vee(1-\gamma) \vee(1-(\gamma \vee \mu))]=1-(\gamma \wedge \mu)$ and int ${ }^{*}[1-($ $\gamma \wedge \mu)] \neq 0$. Hence $\left(X, S^{*}\right)$ is not a fuzzy supra Baire space.

\section{Proposition 4.1}

Let $\left(\mathrm{X}, \mathrm{T}^{*}\right)$ be a fuzzy supra topological space. Then the following are equivalent:

(i) $\left(X, T^{*}\right)$ is a fuzzy supra Baire space.

(ii) int $t^{*}(\chi)=0$, for every fuzzy supra first category Set in $\chi$ in $\left(\mathrm{X}, \mathrm{T}^{*}\right)$.

(iii) $\operatorname{cl}^{*}(\mu)=1$, for every fuzzy supra residual set $\mu \operatorname{in}\left(X, T^{*}\right)$.

\section{Proof}

(1) $\Rightarrow(2)$.

Let $\chi$ be a fuzzy supra first category set in $\left(\mathrm{X}, \mathrm{T}^{*}\right)$.Then $\chi=\mathrm{v}_{\mathrm{i}=1^{\infty}}\left(\chi_{\mathrm{i}}\right)$, where $\chi_{\mathrm{i}}$, s are fuzzy supra nowhere dense sets in $\left(X, T^{*}\right)$.Then, we have int $*$ $(\chi)=$ int $*^{*}\left(v_{i=1}{ }^{\infty}\left(\chi_{i}\right)\right)$. Since $\left(X, T^{*}\right)$ is a fuzzy supra Baire space, int ${ }^{*}\left(v_{i=1}{ }^{\infty}\left(\chi_{i}\right)=0\right.$. Hence int $*(\chi)=0$ for any fuzzy supra first category set $\chi \operatorname{in}\left(X, T^{*}\right)$.
$(2) \Longrightarrow(3)$.

Let $\mu$ be a fuzzy supra residual set in $\left(X, T^{*}\right)$. Then $1-\mu$ is a fuzzy supra first category set in $\left(\mathrm{X}, \mathrm{T}^{*}\right)$. By hypothesis, int ${ }^{*}(1-\mu)=0$. Then $1-\mathrm{cl} *$ $(\mu)=0$. Hence $\operatorname{cl}^{*}(\mu)=1$ for any fuzzy supra residual set $\mu$ in $\left(X, T^{*}\right)$.

$(3) \Longrightarrow(1)$.

Let $\chi$ be a fuzzy supra first category set in $\left(X, \mathrm{~T}^{*}\right)$. $\chi=v_{i=1} 1^{\infty}\left(\chi_{i}\right)$, where $\chi_{i}^{\prime}$ s are fuzzy supra nowhere dense sets in $\left(X, T^{*}\right)$. Now $\chi$ is a fuzzy supra first category set in $\left(X, T^{*}\right)$ implies that $(1-\chi)$ is a fuzzy supra residual set in $\left(X, \mathrm{~T}^{*}\right)$. By hypothesis, we have $\mathrm{cl}^{*}(1-\chi)=1$. Then $1-$ int $^{*}(\chi)=1$. Hence int $*$ $(\chi)=0$. That is, int $*\left(v_{i=1} 1^{\infty}\left(\chi_{i}\right)\right)=0$ where $\chi_{i}^{\prime}$ s are fuzzy supra nowhere dense sets in $\left(X, T^{*}\right)$. Hence $\left(\mathrm{X}, \mathrm{T}^{*}\right)$ is a fuzzy supra Baire space.

\section{Proposition 4.2}

If $\chi$ is a fuzzy supra dense set and fuzzy supra $\mathrm{G}_{\delta}$ -set in a fuzzy supra topological space $\left(X, T^{*}\right)$, then $1-\chi$ is a fuzzy supra first category set in $\left(X, T^{*}\right)$.

\section{Proof}

Since $\chi$ is a fuzzy supra $\mathrm{G}_{\delta}$ set in $\left(\mathrm{X}, \mathrm{T}^{*}\right), \chi$ $=\wedge_{\mathrm{i}=1^{\infty}}\left(\chi_{\mathrm{i}}\right)$ where $\chi_{\mathrm{i}} \in \mathrm{T}^{*}$ and since $\chi$ is a fuzzy supra dense in $\left(\mathrm{X}, \mathrm{T}^{*}\right), \mathrm{cl}^{*}(\chi)=1$, then $\mathrm{cl}^{*}\left(\wedge_{\mathrm{i}=1}{ }^{\infty}\left(\chi_{\mathrm{i}}\right)\right)=1$.But $\mathrm{cl}^{*}\left(\Lambda_{\mathrm{i}=1} 1^{\infty}\left(\chi_{\mathrm{i}}\right)\right) \leq \Lambda_{\mathrm{i}=1}{ }^{\infty} \mathrm{Cl}^{*}\left(\chi_{\mathrm{i}}\right)$.Hence, $1 \leq \wedge_{\mathrm{i}=1}^{\infty} \mathrm{Cl}^{*}($ $\left.\chi_{i}\right)$.(ie) $\wedge_{i=1}^{\infty} \mathrm{cl}^{*}\left(\chi_{i}\right)=1$. Then we have $\mathrm{cl}^{*}\left(\chi_{i}\right)=1$ for each $\chi_{\mathrm{i}} \in \mathrm{T}^{*}$ and hence $\mathrm{cl}^{*}\left(\mathrm{int} \chi_{\mathrm{i}}\right)=1$ which Implies that $1-\mathrm{cl}^{*}$ int $^{*}\left(\chi_{\mathrm{i}}\right)=0$ and hence int* $\mathrm{cl}^{*}\left(1-\chi_{\mathrm{i}}.\right)=0$. Therefore $1-\chi_{i}$.is a fuzzy supra nowhere dense set in $\left(X, T^{*}\right)$. Now 1- $\chi_{i}=1-\wedge_{i=1}{ }^{\infty}\left(\chi_{i}\right)=v_{i=1}^{\infty}\left(1-\chi_{i}\right)$ therefore $1-\chi_{i}=v_{i=1}^{\infty}\left(1-\chi_{i}\right)$ where $\left(1-\chi_{i}\right)$ 's are fuzzy supra nowhere dense sets in $\left(\mathrm{X}, \mathrm{T}^{*}\right)$.Hence $1-\chi_{\mathrm{i}}$ is a fuzzy supra first category set in $\left(\mathrm{X}, \mathrm{T}^{*}\right)$.

\section{Proposition 4.3}

If the fuzzy supra topological space $\left(\mathrm{X}, \mathrm{T}^{*}\right)$ has a fuzzy supra dense and fuzzy supra $G \delta$ set, then $\left(\mathrm{X}, \mathrm{T}^{*}\right)$ is a fuzzy supra Baire space.

\section{Proof}

Let $\chi$ be a fuzzy supra dense and $\mathrm{G} \delta$ set in $\left(\mathrm{X}, \mathrm{T}^{*}\right)$. Then by proposition $3.2,1-\chi$ is a fuzzy supra first category set in $\left(X, T^{*}\right)$ and $(1-\chi)=v_{i=1}{ }^{\infty}\left(\chi_{i}\right)$ where $(1-\chi)^{\prime}$ 's are fuzzy supra nowhere dense sets in $\left(\mathrm{X}, \mathrm{T}^{*}\right)$ But int ${ }^{*}(1-\chi)=1-\mathrm{cl}^{*}(\chi)=1-1=0$ (since $\chi$ is fuzzy supra dense, $\left.\operatorname{cl}^{*}(\chi)=1\right)$. Then $\operatorname{int}^{*}\left(\mathrm{v}_{\mathrm{i}}=1^{\infty}(1-\right.$ $\left.\left.\chi_{i}\right)\right)=$ int $^{*}(1-\chi)=0$ and hence $\left(X, T^{*}\right)$ is a fuzzy supra Baire space.

\section{Proposition 4.4}

If the fuzzy supra topological space $\left(X, T^{*}\right)$ is a fuzzy supra first category space, then $\left(\mathrm{X}, \mathrm{T}^{*}\right)$ is not a fuzzy supra baire space.

Proof: 
Since $\left(X, T^{*}\right)$ is a fuzzy supra first category space, then $v_{i=1}{ }^{\infty}\left(\chi_{i}\right)=1$, where $\chi_{i}^{\prime} s$ are fuzzy supra nowhere dense sets in $\left(X, T^{*}\right)$. Therefore $\operatorname{int}^{*}\left(v_{i=1}^{\infty}\left(\chi_{i}\right)\right)=\operatorname{int}^{*}(1)=1 \neq 0$. Hence int ${ }^{*}\left(v_{i=1}^{\infty}\left(\chi_{i}\right)\right)$ $\neq 0$, where $\chi_{i}^{\prime} s$ are fuzzy supra nowhere dense sets in $\left(X, T^{*}\right)$ and therefore $\left(X, T^{*}\right)$ is not a fuzzy supra Baire space.

\section{Proposition 4.5}

A fuzzy supra topological space $\left(\mathrm{X}, \mathrm{T}^{*}\right)$ is a fuzzy supra Baire space iff $\left.v_{i=1}^{\infty}\left(\chi_{i}\right)\right)=1$ where $\chi_{i}^{\prime}$ 's are fuzzy supra closed set in $\left(X, T^{*}\right)$ with $\operatorname{int}^{*}\left(\chi_{i}\right)=0$, that implies int ${ }^{*}\left(v_{i=1}^{\infty}\left(\chi_{i}\right)\right)=0$

\section{Proof:}

If $\left(X, T^{*}\right)$ is a fuzzy supra Baire space then $\chi_{\mathrm{i}}{ }^{\prime} \mathrm{S}$ are fuzzy supra closed set in $\left(X, T^{*}\right)$ and int* $\left(\chi_{i}\right)=0$ whrer $\chi_{i}$ are fuzzy supra nowhere dense set in $\left(X, T^{*}\right)$.Then $v_{i=1}^{\infty}\left(X_{i}\right)=1$ that implies that 1 is a fuzzy supra first category in $\left(X, T^{*}\right)$. Since $\left(X, T^{*}\right)$ is a fuzzy supra Baire space then by proposition 4.1, int $^{*}(1)=0$. Conversely int ${ }^{*}\left(v_{i=1}^{\infty}\left(\chi_{i}\right)\right)=0$, where $\chi_{i}^{\prime}$ 's are fuzzy supra closed set in $\left(\mathrm{X}, \mathrm{T}^{*}\right)$ with $\operatorname{int}^{*}\left(\chi_{i}\right)=0$.

\section{CONCLUSION}

In this paper, we introduced and studied a new concept Fuzzy Supra Baire Space in Fuzzy Supra topological space. This new concept and the characteristic properties are discussed in depth.

\section{REFERENCES}

[1] Abd El-Monsef, M. E. and Ramadan, A. E, 1987. On fuzzy supra topological spaces, Indian J. Pure Appl.Math., 18 (4) 322-329.

[2] Ahmed S, Chandra Chetia B, 2014. On Certain properties of fuzzy supra semi open sets, International Journal of Fuzzy Mathematics and Systems, 4(1), 93-98.

[3] Chang. C.L. 1968. Fuzzy topological spaces, Journal of Mathematical Analysis and applications, 24, 182-190.

[4] Haworth, R.C., aMcCoy R.A, 1977. Baire spaces, Dissertationes Math., 141,77p.

[5] Mashhour A. S., Allam A. A., Mahmoud F. S and Khedr F. H. 1983. On supratopological spaces, Indian J. Pure and Appl. Math. 4, 14,502-510.

[6] Poongothai E.,Thangaraj G., 2018.Fuzzy Settings on Supra $\sigma$-Baire Spaces, Global Journal for Research Analysis., 7(1), 31-34.

[7] Poongothai. E., Priya.G.2019. Fuzzy Supra Semi Baire spaces, Int. J. Adv. Sci. Eng. 5(3) 1052-1055.
[8] Poongothai.E., Celine.A., On Fuzzy Supra hyperconnected spac es.,J. Phys.: Conf. Ser. 1850012126.

[9] Poongothai.E., Celine.A. 2020.0n Fuzzy Supra Regular Baire Spaces., Advances in Mathematics: Scientific Journal 9(8) 62216227.

[10] Zadeh. L.A. 1965. Fuzzy sets, Informatics and Control, 8, 338-353.

\footnotetext{
All (c) 2022 are reserved by International Journal of Advanced Science and Engineering. This Journal is licensed under a Creative Commons Attribution-Non Commercial-ShareAlike 3.0 Unported License.
} 